\title{
Vulnerabilidade ambiental e áreas de infiltração máxima de água
}

\author{
Environmental vulnerability and areas of maximum water infiltration \\ Pedro Daniel da Cunha', Luciana Gregory Ritter², Willian Fernando de Borba ${ }^{3}$ \\ ' Coordenador do Curso de Engenharia Ambiental da Universidade Federal de Santa Maria/CESNORS, Frederico Westphalen, Brasil. \\ ${ }_{2}^{2}$ Aluna de graduação do curso de Engenharia Ambiental e Sanitária, Universidade Federal de Santa Maria, Santa Maria, Brasil. \\ ${ }^{3}$ Técnico em Agropecuária, Aluno de Graduação do Curso de Engenharia Ambiental, Universidade Federal de Santa Maria, Santa Maria, \\ Brasil
}

\section{Resumo}

A percepção do ser humano de que os recursos do ambiente são limitados, leva a utilização de instrumentos visando o planejamento e gestão do ambiente, como a determinação da vulnerabilidade ambiental, a qual possibilita a avaliação das condições de risco da área em questão a processos geoambientais como a erosão, contaminação dos solos, dos recursos hídricos, perda de aproveitamento agrícola, dentre outros. A avaliação ambiental de uma região permite a identificação de suas potencialidades de uso (ou não uso), de ocupação, de vulnerabilidade, da dinâmica e da complexidade do ecossistema, levando à realização de ações que possibilitem sua preservação e conservação. A partir de um planejamento adequado podem ser evitadas áreas de vulnerabilidade ambiental dentro da bacia hidrográfica, dando a elas, usos compatíveis com o seu estado atual, além da realização de estudos a fim de identificar os fatores que estão desencadeando esse quadro de vulnerabilidade ambiental, para então buscar alternativas de remediação. A análise das áreas de vulnerabilidade ambiental torna-se uma ferramenta valiosa, pois auxilia o gestor na tomada de decisões, minimizando assim os erros de julgamento e otimizando o processo.

\begin{abstract}
The perception of the human being that environmental resources are limited, it takes the use of instruments to the planning and management of the environment, such as the determination of environmental vulnerability, which enables the assessment of the risk of the area in question geo-environmental processes such as erosion, contamination of soils, water resources, loss of agricultural use, among others. Environmental assessment of a region allows the identification of their potential use (or not use), occupation, vulnerability, dynamics and complexity of the ecosystem, leading to the realization of actions that will enable their preservation and conservation. From proper planning can be avoided areas of environmental vulnerability within the watershed, giving them uses compatible with its current state, as well as studies to identify the factors that are triggering this picture of environmental vulnerability, then to seek remediation alternatives. The analysis of the areas of environmental vulnerability becomes a valuable tool as it assists the manager in decision-making, thus minimizing the errors of judgment and optimizing the process.
\end{abstract}




\section{INTRODUÇÃO}

Durante décadas o ser humano tem seu preocupado com o resultado de suas ações sobre a biosfera. No decorrer deste processo, se dá conta que os recursos do Planeta têm limites e que, embora a natureza possua um grande potencial de autodepuração, isso também é limitado. Então, percebe a necessidade de definir até que ponto pode alterar a biosfera e passa a ter certeza de que é preciso planejar as ações quanto ao que faz com relação ao ambiente em que vive (FLORIANO, 2004).

O planejamento e gestão ambiental necessitam de ferramentas ou metodologias que lhe apoiem e permitam facilitar seu processo. Dentre essas metodologias, destaca-se a determinação da vulnerabilidade ambiental, a qual possibilita a avaliação das condições de risco da área em questão a processos geoambientais como a erosão, contaminação dos solos, dos recursos hídricos, perda de aproveitamento agrícola, dentre outros (SANTOS et. al., 2007).

Torna-se cada vez mais urgente o planejamento físico territorial, não só com enfoque socioeconômico, mas também, ambiental, levando-se em consideração não apenas as potencialidades, mas principalmente a fragilidade das áreas com intervenções antrópicas. Para se determinar as potencialidades dos recursos naturais é necessário um estudo dos componentes que dão suporte à vida, sendo eles: solos, relevo, geologia, água, clima e vegetação; na análise da fragilidade, esses componentes devem ser avaliados de maneira integrada, considerando-se sempre as intervenções antrópicas modificadoras dos ambientes naturais (DONHA et al., 2006).

A análise da vulnerabilidade dos sistemas é um indicador da capacidade de suporte ambiental de uma área uma vez que tem como pressuposto básico o conhecimento das características do ambiente natural e da dinâmica dos componentes do mesmo. Através do mapeamento dessa vulnerabilidade é possível analisar e classificar os ambientes em função de seus diferentes graus de suscetibilidade (níveis de vulnerabilidade). De posse dessa informação, é possível indicar áreas onde a vulnerabilidade é mais alta ou mais baixa, adequando assim as intervenções antrópicas à capacidade de suporte ambiental da área, sendo esse um dos instrumentos que norteiam medidas de ordenamento do uso do território (NOBRE, 2008).

Tratando-se da vulnerabilidade a contaminação dos aquíferos, Kemerich et al. (2010) afirmam que de um modo geral, o termo vulnera- bilidade é entendido como sendo a suscetibilidade do aquífero à contaminação.

A contaminação dos aquíferos tem se tornado um dos problemas mais preocupantes nas questões de gestão dos recursos hídricos subterrâneos, pois estes são considerados reservatórios estratégicos para a humanidade (CUTRIM e CAMPOS, 2010).

Sendo assim, o objetivo desta pesquisa foi demonstrar a importância da análise da vulnerabilidade ambiental em bacias hidrográficas, verificando assim, a possibilidade de ocorrer à contaminação das águas subterrâneas.

\section{A BACIA HIDROGRÁFICA COMO UNI- DADE BÁSICA PARA ESTUDOS AMBIEN- TAIS}

Uma bacia hidrográfica compreende essencialmente um rio principal e seus afluentes delimitados por um divisor de águas, mas dentro desta bacia existem inúmeros fatores que exercem ações positivas e negativas, que influenciam diretamente na qualidade do seu meio ambiente. A gestão ambiental é um processo de articulação das ações dos diferentes agentes sociais que interagem em um dado espaço com vistas a garantir a adequação dos meios de exploração dos recursos ambientais - naturais, econômicos e sócio-culturais - às especificações do meio ambiente com base em princípios e diretrizes previamente acordados e definidos (LANNA, 2000).

A bacia hidrográfica é uma área topograficamente definida pela drenagem de um canal fluvial ou por um sistema de canais fluviais conectados, de tal forma que toda água drenada nesse espaço tenha uma única saída. Cada bacia hidrográfica pode ser subdividida em bacias menores, o que significa dizer que uma bacia hidrográfica é formada por um conjunto de pequenas bacias (ROSA et al., 2004).

A LEI No 9.433, de 08 de janeiro de 1997, que Institui a Política Nacional de Recursos Hídricos, que cria o Sistema Nacional de Gerenciamento de Recursos Hídricos, prevê no seu Artigo $1^{\circ}$, que a bacia hidrográfica é a unidade territorial para implementação da Política Nacional de Recursos Hídricos e atuação do Sistema Nacional de Gerenciamento de Recursos Hídricos.

A LEI N ${ }^{\circ} 10.350 / 1994$ institui o Sistema Estadual de Recursos Hídricos e estabelece, para os rios do estado, a formação de um comitê de gerenciamento, o Comitê de Bacia. Segundo a SEMA (2004), o estado do Rio Grande do Sul, de 
acordo com a referida lei, foi dividido em Regiões Hidrográficas, que foram subdivididas em bacias hidrográficas, totalizando, até o presente momento, 23 unidades. Para cada uma destas está previsto a formação de um comitê para a gestão integrada dos seus recursos hídricos.

A bacia hidrográfica pode ser considerada um ente sistêmico, onde se realizam os balanços de entrada proveniente da chuva e saída de água através do exutório, permitindo que sejam delineadas bacias e sub-bacias, cuja interconexão se dá pelos sistemas hídricos. Sobre o território definido como bacia hidrográfica é que se desenvolvem as atividades humanas. Todas as áreas urbanas, industriais, agrícolas ou de preservação fazem parte de alguma bacia hidrográfica. Pode-se dizer que, no seu exutório, estarão representados todos os processos que fazem parte do seu sistema. O que ali ocorre é consequência das formas de ocupação do território e da utilização das águas que para ali convergem (PORTO; PORTO, 2008).

As bacias hidrográficas devem compreender espaços de desenvolvimento econômico e preservação ambiental, integrando uma visão conjunta do comportamento das condições naturais e das atividades humanas nelas desenvolvidas (GUERRA; CUNHA, 1996), fazendo-se necessário um planejamento sustentável de sua utilização.

Os fenômenos acorridos dentro de uma bacia, sejam eles de origem natural ou antrópica, interferem na dinâmica sistêmica, na quantidade e qualidade dos cursos de água e as medidas de algumas de suas variáveis (solo, clima, vegetação, relevo, entre outros) permitem compreender a soma desses fenômenos (CORSEUIL, 2006).

A avaliação ambiental de uma região permite a identificação de suas potencialidades de uso (ou não uso), de ocupação, de vulnerabilidade, da dinâmica e da complexidade do ecossistema, levando à realização de ações que possibilitem sua preservação e conservação (MACEDO, 1995).

Segundo Botelho e Silva (2004), cresceu enormemente o valor da bacia hidrográfica como uma unidade de análise e planejamento ambiental e estudos como erosão, manejo e conservação do solo, água e planejamento ambiental, são aqueles que mais têm utilizado a bacia hidrográfica como unidade de análise. Uma importante ferramenta para auxiliar nas definições dos usos de uma bacia é o zoneamento ambiental, que é de fundamental importância, pois atua no sentido de direcionar propostas em função das características naturais de cada área da bacia. Contribui para o gerenciamento dos recursos hídricos, que se torna cada vez mais necessário em virtude da multiplicidade dos usos da água decorrente do processo de industrialização, de urbanização e de agricultura intensiva.

\section{A ATUAÇÃO E A EFETIVIDADE DOS COMITÊS DE GERENCIAMENTO DE RE- CURSOS HÍDRICOS}

Os comitês de gerenciamento de bacias hidrográficas são colegiados instituídos oficialmente pelo Governo do Estado que representam a instância básica de participação da sociedade no Sistema Estadual de Recursos Hídricos (SEMA, 2008). Estão previstos no Sistema Nacional de Gerenciamento de Recursos Hídricos - SINGRH (instituído pela Lei Federal n ${ }^{\circ}$ 9433/1997), sendo órgãos colegiados onde são debatidas as questões regionais referentes à gestão das águas.

Os comitês de bacias hidrográficas configuram-se como instituições relativamente recentes no Brasil, criadas nas duas últimas décadas do século $\mathrm{XX}$, em um contexto de descentralização da gestão implementada pelo Estado, notadamente a partir da Constituição Federal de 1988 - CF/1988, onde a competência de alguns aspectos da gestão de recursos hídricos, bem como da gestão ambiental, está relacionada aos três entes federados, dispostas no art. 23 da CF.

Desse modo, representantes dos três setores compõem o Comitê de Bacia Hidrográfica: representantes do poder público (União, estados, Distrito Federal e municípios, conforme a abrangência da bacia), usuários das águas e organizações da sociedade civil ligadas a recursos hídricos. Sendo que o número de representantes de cada 'setor' e os critérios para sua indicação são estabelecidos nos regimentos internos dos próprios comitês (algumas leis estaduais também explicitam esta composição), limitando a representação dos poderes executivos à metade do total de membros (CARDOSO, 2003).

Os comitês têm atribuições, as quais estão especificadas no art. 19 da Lei $\mathrm{n}^{\circ} 10.350 / 94$, tais como promover o debate das questões relacionadas aos recursos hídricos da bacia, aprovar e acompanhar a execução do Plano de Recursos Hídricos da Bacia, estabelecer os mecanismos de cobrança pelo uso de recursos hídricos e sugerir o valor a ser cobrado, estabelecer critérios e promover o rateio de custo das obras de uso múltiplo, de interesse comum ou coletivo, arbitrando em primeira instância, os conflitos relacionados a recursos hídricos. Em suma, os comitês devem participar comunitariamente do SERH-RS como um todo, configurando-se em um espaço onde se possa incorporar democraticamente na tomada de 
decisão a vertente comunitária, e, não somente, a vertente técnica proveniente de técnicos do governo ou de empresas contratadas (DULAC et al., 2012).

De acordo com a Legislação Federal e Estadual de Recursos Hídricos, os comitês de bacia hidrográfica devem promover a gestão participativa e social, sendo que os mesmos devem ser compostos por vários seguimentos da sociedade, entre eles: setor dos usuários, sociedade civil organizada e órgãos públicos envolvidos na questão dos recursos hídricos. Cabe aos comitês amenizar conflitos entre os diferentes atores sociais envolvidos, a fim de que as necessidades sejam atendidas, mas sempre levando em consideração a conservação das águas (MEIER, 2011).

Funcionando como fórum integrador de políticas, o comitê tem o potencial de articular a política de recursos hídricos com a política ambiental, socioeconômica e de uso do solo, entre outras, possibilitando gerenciar de forma integrada e sustentável a utilização e conservação dos recursos naturais da bacia hidrográfica (MASCARENHAS, 2006).

Os comitês desempenham um papel estratégico na Política de Recursos Hídricos, pois tem o potencial de sintetizar suas diretrizes. No caso da Política de Recursos Hídricos gaúcha, a qual preconiza uma gestão descentralizada - no nível espacial das bacias, participativa e integrada - o Comitê de Bacia configura-se em um espaço institucional o qual pode ser caracterizado como uma arena de tomada de decisões para o compartilhamento de interesses e integração de políticas dos setores usuários da água e da sociedade civil. Assim, o êxito de seu funcionamento em certa medida significa o êxito da própria política das águas. Sua legitimidade tem sido conferida não apenas pela própria lei e pelas políticas nacional e estaduais, mas por políticas paralelas que têm sido implementadas tanto no âmbito nacional como no estadual e, em alguns casos, até no municipal (CARDOSO, 2003).

Ao atribuir, aos comitês o gerenciamento dos recursos hídricos centralizado, o mesmo, torna-se possível um novo mecanismo de cooperação multilateral entre a esfera federal e as demais, na solução de problemas regionais, sobretudo nas regiões conturbadas (NASCIMENTO; VILLAÇA, 2008).

No entanto, os comitês têm enfrentado dificuldades na sua implementação, como é relatado por Costa (2002) que, com base em sua experiência, afirma que os problemas dos comitês começam com a ausência de pautas concretas, diminuindo o número de participantes das reuniões, e com a burocracia do Estado.

Os comitês estão centrados na participação social, sendo esta outra dificuldade para o seu funcionamento. Para que ela ocorra verdadeiramente, necessita de representação e representatividade de seus membros. Segundo Meier (2011), a falta de representatividade dos comitês junto à sociedade pode estar ancorada na falta de representatividade da sociedade junto aos comitês.

O processo de financiamento dos comitês é outro segmento que não funciona, dificultando a sua atuação, e este aspecto só terá mudanças quando se instituir a cobrança pelo uso dos recursos hídricos (PAIM, 2010).

Através das discussões, deliberações e projetos aprovados pelo comitê, temos acesso às decisões mais importantes, quer quanto à aplicação e ao uso de suas atribuições, quer quanto à recursos a serem aplicados na Bacia.

Segundo Cury (2005), através dos documentos oficiais do Comitê, como as atas das plenárias, é possível analisar os diversos segmentos representados no Comitê e a atuação de suas forças, os participantes mais ativos, os temas debatidos e o destino dado a eles diante do fato de terem sido discutidos num fórum regional.

\section{GEOLOGIA, CLIMA E VEGETAÇÃO}

$\mathrm{Na}$ realização do diagnóstico físico da área de uma bacia hidrográfica, é fundamental o levantamento detalhado de parâmetros como: topografia, geologia, rede de drenagem, solos, clima e vegetação (BELTRAME, 1994).

O estudo geológico dos terrenos da bacia tem por objetivo principal classificá-los quanto à maior ou menor permeabilidade, característica esta que intervém, fundamentalmente, na rapidez e no volume das enchentes e na parcela levada às vazões de estiagens pelos lençóis subterrâneos; em certos terrenos, entretanto, o estudo deve ser aprofundado principalmente quanto à localização de lençóis aquíferos, ao escoamento subterrâneo e à origem das fontes. Ainda, a cobertura vegetal, especialmente as florestas e campos cultivados, soma sua influência à dos fatores geológicos para condicionar a rapidez do escoamento superficial, as taxas de evaporação e a capacidade de retenção (PAIVA; PAIVA, 2001).

Além disso, o conhecimento das condições climáticas se faz necessária, uma vez que a vegetação, o relevo e o escoamento superficial são determinados pelas condições climáticas da região (GALVÍNCIO et al., 2007).

A ação do homem no planejamento e no desenvolvimento da ocupação do espaço na terra requer, cada vez mais, uma visão ampla sobre as necessidades da população, os recursos terrestres e aquáticos disponíveis e o conhecimento sobre o comportamento dos processos naturais na bacia, para, racionalmente, compatibilizar necessidades crescentes com recursos limitados (TUCCI, 2000). 


\section{SOLOS}

A dinâmica no mecanismo da formação dos solos se traduz em processos de fragmentação de natureza físico-química e decomposição das rochas, além do transporte da sedimentação e da evolução pedogênica (ROCHA, 2005). Sua origem resulta da alteração de rochas e sedimentos pela ação das variações climáticas (intensidade das chuvas, variação de temperatura) e dos organismos vivos (fauna e flora), nas mais diversas situações da paisagem ao longo do tempo (STRECK, 2008).

A interação entre os fatores que originam o solo é que determinará o seu grau de desenvolvimento e, portanto, sua classificação. Esta é feita através da caracterização de peculiaridades da formação, ocorrência, constituição física e química e da sua capacidade de uso (SILVA et al., 2004).

No que diz respeito às propriedades físicas do solo, eles são constituídos por uma mistura de partículas sólidas de natureza mineral e orgânica, ar e água, formando um sistema trifásico, sólido, gasoso e líquido.

Através da física de solos são definidas, qualitativa e quantitativamente, as propriedades físicas, bem como suas determinações e seu controle, com a finalidade principal de entender os mecanismos que governam a funcionalidade dos solos e seu papel na biosfera. A importância prática de se entender o comportamento físico do solo está associada ao seu uso e seu manejo apropriado, ou seja, orientar irrigação, drenagem, preparo e conservação de solo e água (REINERT; REINERT, 2006).

Em função do manejo a que está submetido, o solo tanto é passível de degradação quanto de melhoramento em seu potencial produtivo. Quando ocorre a degradação da estrutura do solo, tem-se como efeito imediato o aumento da densidade, redução da macroporosidade e armazenamento de água ao longo do perfil, caracterizando a compactação desse solo (STONE; MOREIRA, 2000; ALVES, 2001).

Quando ocorre a compactação do solo, quer seja natural ou antropogênica, ocorre redução da infiltração de água no perfil do solo e no comportamento da sua redistribuição e retenção, em virtude das alterações da porosidade do solo, principalmente em relação à distribuição de tamanho de poros (ALVES, 2001).

Várias são as maneiras pelas quais a qualidade física do solo pode se manifestar; são exemplos de má qualidade física dos solos a baixa capacidade de infiltração de água, o escoamento superficial, a baixa aeração, o sistema radicular reduzido e a dificuldade de mecanização. A condição física é considerada boa quando os solos exibem condição oposta ou ausência dos problemas já mencionados; frequentemente, um solo apresenta todos esses problemas físicos simultaneamente; o que é importante frisar é que todos esses sintomas têm uma causa em comum - a estrutura do solo degradada (DEXTER, 2004). A degradação da estrutura do solo pode comprometer o desenvolvimento das plantas e, consequentemente, a produção agrícola (RICHART et al., 2005).

Em vista, a água ocupa os espaços porosos do arranjo físico das partículas da fase sólida competindo e, frequentemente, concorrendo com a fase gasosa do solo. Da água que chega ao solo, uma parte é armazenada; a água do solo é altamente dinâmica, exibindo variação no tempo e no espaço, sobretudo perto da superfície do solo, devido à evaporação e à atividade das raízes das plantas. Mudanças no conteúdo de água do solo e no seu estado de energia afetam muito as suas propriedades mecânicas, incluindo resistência, compactabilidade e penetrabilidade, podendo causar mudanças na densidade de solos expansivos (OR; WRAITH, 2000).

A retenção de água é primariamente dependente da distribuição de tamanho de partículas do solo, estrutura, mineralogia e matéria orgânica; numa segunda consideração, o uso e o manejo do solo podem afetar a retenção e o conteúdo de água no solo. O melhor aproveitamento da água capilar pode se tornar fundamental para o incremento de produção e das condições do solo, pois, à medida que é submetido a muitos ciclos de umedecimento e secagem, o solo pode ter suas propriedades físicas prejudicadas como, por exemplo, um aumento na densidade do solo (FASSBENDER, 1982).

\section{CARACTERÍSTICAS FÍSICAS DO SOLO QUE INFLUENCIAM NA INFILTRAÇÃO E NA VULNERABILIDADE}

\section{I Textura do solo}

A textura do solo refere-se à proporção relativa das partículas de areia, silte e argila que compõem a terra fina do solo (fração menor que $2 \mathrm{~mm}$ ). Ela afeta muitas propriedades químicas e físicas do solo, tais como a capacidade de troca de cátions (CTC), a retenção de água, a erodibilidade do solo, a infiltração de água e a drenagem, entre outros (STRECK et al., 2008). A análise granulométrica permite classificar os componentes sólidos em classes, de acordo com seu diâmetro, sendo a parte sólida do solo constituída por material 
inorgânico e orgânico.

No material que constitui a porção mineral do solo podem ser encontrados desde fragmentos de rochas até partículas com dimensões extremamente reduzidas. Solos argilosos e solos arenosos diferem, distintamente, em suas propriedades e características. Os primeiros apresentam em diferentes graus, certa dureza quando secos e plásticos e pegajosos quando molhados, assim como retém mais água que os arenosos. Por sua vez, os solos arenosos, além de geralmente não apresentarem características de dureza, plasticidade e viscosidade, secam mais rapidamente que os argilosos. De uma maneira geral, os solos argilosos têm maior capacidade de retenção de água e nutrientes que os arenosos. (LIMA; LIMA, 2000). Partículas de argila são caracterizadas por tamanhos extremamente pequenos, grande áreas externas por unidade de peso e pela presença de cargas em sua superfície; por isso atraem nutrientes e água (BRADY, 1989).

\subsection{Porosidade do solo}

O volume do solo não ocupado por partículas sólidas, incluindo todo o espaço poroso ocupado pelo ar e pela água, constitui a porosidade. A porosidade pode ser subdividida em macroporos e microporos. Entre as partículas maiores, como a areia ou entre agregados, predominam poros grandes (macroporos); entre partículas pequenas, como a argila, predominam poros pequenos (microporos). Os macroporos são responsáveis pela aeração, pela movimentação de água e pela penetração de raízes, os microporos, por sua vez, são responsáveis pela retenção de água no solo (LIMA; LIMA, 1996).

A variação composicional, em função da porosidade do solo, ocorre por vários fatores, tais como superfície específica, atividade da fração sólida (argila $>$ silte $>$ areia), grau de intemperismo dos minerais, matéria orgânica em suspensão na água gravitacional, diferença entre a taxa rápida de liberação e de retenção das espécies químicas (absorção, adsorção e atividade microbiana) e os processos mais lentos de difusão e de convecção entre os micro e macroporos, resultando num gradiente de concentração. A soma dos fenômenos deveria resultar numa distribuição complexa e altamente variável dos íons na porosidade do solo (GLOAGUEN et al., 2009).

As taxas de infiltração de água no solo são diretamente afetadas pela quantidade e a maneira como os poros estão distribuídos no solo. Esta distribuição depende da textura e da estrutura do solo, podendo ser obtida através da curva característica de água no solo. A água presente nos macroporos é facilmente drenada pela ação da gravidade e parte da água retida nos microporos não é disponível às plantas (FIORIN, 2008).

\subsection{Condutividade hidráulica saturada (K0)}

Os processos de infiltração de água no solo, projetos de irrigação e drenagem, as perdas de solo por erosão e de substâncias químicas por lixiviação são geralmente relacionados ao fluxo de água nos solos, o qual influencia toda a utilização dos recursos solo e água. (MESQUITA; MORAES, 2004).

Dentre as variáveis que influenciam esse fluxo, a condutividade hidráulica do solo se destaca por ser um parâmetro que representa a facilidade com que o solo transmite água. O valor máximo de condutividade hidráulica é quando o solo se encontra saturado, e é denominado condutividade hidráulica saturada (REICHARDT, 1990). A partir da $\mathrm{K}(\mathrm{o})$ e utilizando modelos matemáticos podese determinar a condutividade hidráulica do solo e assim obter informações sobre o movimento de água e solutos nos solos.

A condutividade hidráulica é uma das propriedades físicas do solo mais importantes na determinação quantitativa e qualitativa do movimento de água no solo e no dimensionamento de sistemas de drenagem (FEITOZA, 2006).

Como pode ser observado nos trabalhos de Silva e Katto (1997) e Ankeny et al., (1990), estes autores, trabalhando com diferentes sistemas de cultivo, constataram que esses sistemas alteram a porosidade e as propriedades hidráulicas dos solos cultivados. Variações na velocidade de infiltração estão relacionadas com atributos como densidade do solo, macro e microporosidade e condutividade hidráulica, com o qual, segundo Freire (1979), é um parâmetro importante no manejo da água no solo. Trata-se de um processo físico de extrema complexidade, dado que o solo é um meio heterogêneo, com ampla variabilidade espacial, apresentando características que sofrem alterações diferenciadas no tempo e no espaço. Como essa propriedade é específica para cada solo, e devido aos fenômenos da água no solo serem dinâmicos e influenciáveis pelas camadas subjacentes, torna-se necessário identificá-la de forma global, na superfície do solo, para, a partir dessa caracterização, para cada tipo de manejo, compreender o todo.

\subsection{Uso e ocupação do solo}

O estudo do uso da terra e ocupação do solo consiste em buscar conhecimento de toda sua utilização por parte do homem ou, quando não 
utilizado pelo homem, a caracterização dos tipos de categorias de vegetação natural que revestem o solo, como também suas respectivas localizações. De forma sintética, a expressão "uso da terra ou uso do solo" pode ser entendida como sendo a forma pela qual o espaço está sendo ocupado pelo homem (ROSA, 2007). A ocupação do solo interfere diretamente nos recursos hídricos bem como da sua gestão, pois o uso inadequado pode originar processos erosivos, compactação, aumento da salinidade do solo e consequentemente o assoareamento de corpos de água e perdas em termos qualitativos e quantitativos.

Os processos de erosão intensos, desertificação, inundações, assoreamentos de cursos d'água têm sido exemplos cotidianos de mau uso. De acordo com Linhares et al., (2005), a utilização do solo desempenha um importante papel no ciclo hidrológico, com a vegetação tendo influência direta no processo de erosão, na qualidade da água, na dinâmica de nutrientes, na proteção de mananciais e na produção de água.

Santos (2003) afirma que a bacia hidrográfica é a melhor unidade territorial de investigação, pesquisa e planejamento, devido à possibilidade de observação de fenômenos naturais ou antrópicos que refletem, diretamente, seus resultados em determinado limite observável da paisagem.

Segundo Anderson et al. (2005), o mapeamento da cobertura vegetal e seu monitoramento mostram-se de extrema importância, e existe um esforço por parte da comunidade científica em melhorar a acurácia destes estudos. Estes trabalhos visam observar as mudanças devido a fatores naturais e antrópicos, buscar uma maior eficiência nas elaborações de planos de manejo de recursos naturais, assim como na análise da paisagem, delimitar áreas prioritárias para a conservação ou, ainda, realizar estudos que envolvem tópicos sobre mudanças globais, modelagens de ciclos biogeoquímicos, estimativas de emissão de carbono, dentre outros.

Entre os fatores da degradação da paisagem, seja nas áreas rurais, seja nas áreas urbanas, a principal causa, segundo Guerra e Cunha (1996), é o manejo inadequado do solo. $\mathrm{O}$ crescente interesse sobre uso e cobertura do solo desperta interesse em toda a sociedade, pois, além de monitorar os possíveis impactos ambientais, pode-se acompanhar o desenvolvimento sócio-econômico de um local, tanto em escala municipal como regional e, até mesmo, global (MONTEBELO et al., 2005).

O conhecimento do uso e da cobertura do solo favorece para que medidas que garantam a preservação e a manutenção do meio ambiente e a gestão do espaço seja adequada à realidade. (SCHLINDWEIN et al., 2007). França \& Ferreira (2005) destacam que muitos ciclos ambientais dependem do equilíbrio de florestas como a Amazônia e que sua destruição acarreta em mudanças no clima de forma global, regional e local.

\subsection{Vulnerabilidade natural à contaminação da água subterrânea}

A vulnerabilidade significa a maior suscetibilidade de um aquífero de ser adversamente afetado por uma carga contaminante imposta. Os autores complementam: "É um conceito inverso da capacidade de assimilação de contaminantes de um corpo receptor de água superficial, com a diferença de que os aquíferos possuem uma cobertura de substratos que proporciona maior proteção" (FOSTER; HIRATA, 1993).

Ribeira (2004) comenta que em hidrologia subterrânea a vulnerabilidade pode consistir na subdivisão em dois termos: vulnerabilidade natural e vulnerabilidade específica. Vrba e Zaparozec (1994 apud RIBEIRA, 2004) definem a vulnerabilidade natural, ou intrínseca, dos aquíferos como a soma de uma série de atributos ou características dos mesmos que são: o solo, a zona não saturada, os parâmetros hidráulicos do aquífero e a recarga que controlam a aptidão do mesmo para tomar frente a um impacto indeterminado e sua capacidade de autorecuperação. Os mesmos autores definem a vulnerabilidade específica como a aptidão do aquífero para fazer frente a um tipo de contaminante/impacto concretamente, dentro de um contexto conjuntural (sócio econômico) específico. A diferença é que, no caso anterior, os parâmetros que medem esta vulnerabilidade estão, também, definidos pelo impacto.

A vulnerabilidade natural se costuma calcular e expressar em termos hidrogeológicos, como por exemplo, a profundidade do nível freático, a permeabilidade, etc. Pelo contrário, a vulnerabilidade específica da água subterrânea costuma-se expressar em termos de riscos frente a um determinado impacto (RIBEIRA, 2004, p. 20).

Até a década de 70, acreditava-se que as águas subterrâneas estavam naturalmente protegidas da contaminação pelas camadas de solo e rochas. Entretanto, a partir de então, passaram a ser detectados traços da presença de contaminantes em águas subterrâneas, e diversos estudos têm sido conduzidos no sentido de avaliar a sua seguridade. Atualmente sabe-se que vários fato- 
res podem comprometer sua qualidade (SILVA; ARAÚJO, 2003).

Ainda segundo os autores, quanto maior a capacidade de infiltração da água, maior será o perigo de contaminação das águas subterrâneas. Assim, terrenos de composição arenosa e porosa apresentam uma maior relação entre porosidade e permeabilidade, sendo mais suscetíveis ao fluxo e ao espalhamento de plumas contaminantes. Já os terrenos argilosos, que são de baixíssima permeabilidade, dificultam o fluxo de fluidos, sejam eles contaminantes ou não.

Ribeira (2004) afirma que os aquíferos livres granulares e os aquíferos carbonatados cársticos situam-se como os grupos mais vulneráveis diante de um contaminante potencial. Os primeiros devido à sua relativa e pequena capacidade de autodepuração do terreno. É importante que a posição local do nível freático nesse tipo de aquífero condicione seu grau de vulnerabilidade.

No caso do aquífero Cárstico, o mesmo autor comenta que a sua alta vulnerabilidade natural se atribui à velocidade de circulação da água subterrânea relativamente alta e sua escassa interação contaminante-rocha, que provoca uma elevada capacidade de propagação neste meio.

Uma caracterização aproximada da ideia de risco de poluição das águas subterrâneas consiste na associação e na interação da vulnerabilidade natural do aquífero com a carga poluidora aplicada no solo ou em subsuperfície. Isso significa que se pode ter uma situação de alta vulnerabilidade, porém sem risco de contaminação, se não existir carga poluidora significativa, ou vice-versa. A carga poluidora pode ser controlada ou modificada; mas o mesmo não ocorre com a vulnerabilidade natural, que é uma propriedade intrínseca (KEMERICH et al., 2011).

Com relação aos fatores que influenciam a vulnerabilidade dos aquíferos, Ribeira (2004) comenta que a vulnerabilidade natural aumenta quanto menor for sua capacidade de atenuação ao impacto e quanto maior for sua acessibilidade.

Aprofundando mais, podem-se discriminar os seguintes grupos de parâmetros que influenciam na determinação da vulnerabilidade:

1) As características geológicas do aquífero: porosidade primária, tipo e grau de fraturação;

2) Os parâmetros hidráulicos do aquífero: sua condutividade hidráulica e sua transmissividade;

3) O regime de recarga do aquífero: tanto em seus aspectos quantitativos como a localização espacial, extensão e magnitude;
4) A existência, a continuidade e a espessura da zona saturada e no caso de existir as características hidrológicas e de composição dos níveis suprajacentes do solo.

A atividade humana em superfície pode alterar e induzir novos mecanismos de recarga do aquífero, modificando a taxa, a freqüência e a qualidade na recarga de águas subterrâneas. $\mathrm{O}$ entendimento desses mecanismos e a correta avaliação de tais modificações são fundamentais para a determinação do risco de contaminação das águas subterrâneas (OSÓRIO, 2004, p. 75).

É importante lembrar que se existir um aquífero com elevada vulnerabilidade não significa que este já esteja contaminado, mas sim que esta área é de risco. Sua contaminação ou não vai depender das atividades antrópicas que estão sobre ele localizadas, ou seja, ele pode ser altamente vulnerável, mas não correr nenhum risco de ser contaminado por estar localizado numa área distante de fontes contaminantes, principalmente da presença humana, tais como lixões, cemitérios, distritos industriais entre outros (SANTOS, 2010).

Os componentes da vulnerabilidade de um aquífero não são diretamente mensuráveis, mas, sim, determinados por meio de combinações de outros fatores. Além disso, dados referentes a vários fatores não podem ser facilmente estimados ou não estão disponíveis, o que obrigam, na prática, uma simplificação no número de parâmetros requeridos. (KEMERICH et al., 2011).

Nesse sentido, a metodologia "GOD", G groundwater hydraulic confinement; $\mathrm{O}$ - overlaying strata; D - depth to groundwater table, reduz o número desses fatores para apenas três, que são:

1) Tipo de ocorrência de água subterrânea ou condição do aquífero $(G)$;

2) Características dos estratos acima da zona saturada, em termos de grau de consolidação e tipo litológico $(\mathrm{O})$;

3) A profundidade do nível da água (D).

Destacam-se vários métodos de avaliação de vulnerabilidade natural de aquíferos, dentre eles, o "GOD" e o DRASTIC. Segundo Foster et al. (2003), os fatores e pesos atribuídos na avaliação do índice de vulnerabilidade à contaminação no Método DRASTIC são:

$\mathrm{D}=$ Profundidade à água subterrânea (x5);

$\mathrm{R}=$ Taxa de recarga natural ( $\mathrm{x} 4)$;

$\mathrm{A}=$ Características do meio aquífero $(\mathrm{x} 3)$;

$\mathrm{S}=$ Características do solo (x2);

$\mathrm{T}=$ Aspecto topográfico $(\mathrm{x} 1)$; 
$\mathrm{I}=$ Impacto (efeito) da zona não saturada (vadoza) (x5);

$\mathrm{C}=$ Condutividade hidráulica $(\mathrm{x} 3)$.

A metodologia DRASTIC (ALLER et al. 1987) foi desenvolvida pela National Ground Water Association e é empregada pela Agência de Proteção Ambiental Norte Americana (USEPA), constituindo-se num modelo qualitativo para avaliar a potencial poluição das águas subterrâneas. $\mathrm{O}$ cenário hidrogeológico inclui os principais fatores geológicos e do meio aquífero que conferem o nome à metodologia, sendo que para cada um dos fatores são atribuídos pesos, os quais estão relacionados, a maior ou a menor importância do fator, na avaliação da vulnerabilidade dos aquíferos.

\section{6 Áreas de infiltração máxima de água}

A infiltração da água no solo é um processo importante da fase terrestre do ciclo hidrológico, uma vez que determina quanto de água da chuva penetra no solo e quanto escoa superficialmente. As atividades de uso da terra exercem significativa influência sobre a infiltração, e o homem pode, assim, modificar a capacidade de infiltração dos solos através do manejo. A meta maior de um programa de manejo integrado de microbacias hidrográficas deve ser a manutenção das condições ótimas da infiltração (LIMA, 2007).

A mensuração da taxa de infiltração de água possibilita avaliar a quantidade de água que efetivamente infiltra no solo e o escoamento superficial que possa acontecer (FIORIN, 2008).

Segundo Guerra (2000), a taxa de infiltração e a retenção de água pelo solo são importantes, pois auxiliam na definição de políticas de proteção e de conservação do solo e da água, planejamento de sistemas de irrigação e drenagem, bem como na composição de uma imagem mais real da retenção, do movimento, da redistribuição e da conservação da água no solo.

Alguns atributos físicos do solo podem ser alterados pelas práticas de manejo e, dessa maneira, a taxa de infiltração de água no solo modificase, permitindo, em alguns casos, o aumento do escoamento superficial e a aceleração das perdas de solo e de água, alterando o equilíbrio hidrológico natural do sistema. Os valores da taxa de infiltração estável são imprescindíveis aos modelos utilizados na descrição de infiltração de água no solo e, também, ao planejamento e ao manejo dos sistemas de irrigação, drenagem e conservação de solo e de água (PANACHUKI, 2003).

O conceito de infiltração no ciclo hidrológico foi introduzido por Horton (1933). Este autor definiu "capacidade de infiltração" (fc) como sendo a taxa máxima com que um dado solo, em determinadas condições, pode absorver água. Quando a intensidade da chuva for inferior ao valor de fc, então a infiltração ocorre a uma taxa menor, referida como "taxa real de infiltração", ou, simplesmente, infiltração (f). Segundo este conceito Hortoniano, toda vez que a intensidade da chuva for maior que a capacidade de infiltração (fc), ocorre escoamento superficial. Por outro lado, quando a intensidade da chuva for menor que o valor de fc, toda a água se infiltra (f) e não ocorre escoamento superficial (ZAKIA, 1998).

Lima (2008) diz que, em resumo, as características do meio permeável (o meio poroso onde ocorre a infiltração) são governadas pelo tipo de solo, sua textura e estrutura, a quantidade e o tipo de argila que este contém, a espessura e a profundidade de suas camadas mais permeáveis e o uso a que foi submetido no passado.

De acordo com as diferenças encontradas no que diz respeito à infiltração, os solos podem ser classificados em quatro grupos principais (USDA, 1972; LIMA, 2008):

"A" - SOLOS COM ALTA CAPACIDADE DE INFILTRAÇÃO (ou baixo potencial de Runoff): quando totalmente molhados, consistindo de camadas de areias e cascalhos profundos, de drenagem boa a excessiva. Tais solos apresentam alta taxa de transmissão de água.

"B" - SOLOS COM CAPACIDADE DE INFILTRAÇÃO MODERADA: quando totalmente molhados, consistindo de solos de profundidade moderada a alta, drenagem moderada a alta, textura moderadamente fina a moderadamente grosseira. Tais solos apresentam taxas moderadas de transmissão de água.

"C" - SOLOS COM BAIXA CAPACIDADE DE INFILTRAÇÃO: quando totalmente molhados, consistindo de solos contendo camadas impermeáveis que impedem o movimento descendente da água, ou solos de textura moderadamente fina a fina. Tais solos apresentam baixas taxas de transmissão de água no perfil.

"D" - SOLOS COM CAPACIDADE DE INFILTRAÇÃO MUITO BAIXA (alto potencial de Runoff): quando totalmente molhados, consistindo de solos argilosos com alto potencial de intumescimento ou com lençol freático permanentemente superficial ou com camada de impedimento superficial ou solos rasos assentados sobre estrato impermeável. Tais solos apresentam taxa de transmissão de água muito baixa.

Dessa maneira, pode-se dizer que o conhecimento referente ao comportamento do solo, quanto à infiltração de água e às perdas de solo e 
de água em cada sistema de exploração agrícola, é de grande importância, pois permite que sejam estabelecidas comparações em relação aos aspectos qualitativos e quantitativos entre os sistemas em uso, possibilitando a escolha daquele que melhor se adapta às condições específicas de cada região (PANACHUKI, 2003).

\subsection{Contaminação química do solo em função do uso e da ocupação}

O termo metal pesado é utilizado, de maneira um pouco confusa na literatura, segundo Amaral Sobrinho et al., (1992) para definir elementos com densidade atômica $>6 \mathrm{gcm}^{3}$, que estejam essencialmente ligados à poluição. Os metais podem ser classificados em metais alcalinos (Li, Na, K, Rb, Cs, Fr) coluna $1 \mathrm{~A}$, metais alcalinoterrosos (Be, $\mathrm{Mg}, \mathrm{Ca}, \mathrm{Sr}, \mathrm{Ba}, \mathrm{Ra}$ ) coluna $2 \mathrm{~A}$, e os demais metais, como é o caso do cádmio. Esse termo é o mais empregado para designar elementos classificados como poluentes do ar, da água, do solo e dos alimentos (CRUVINEL, 2009).

Os metais pesados possuem número atômico maior que 20, podem ser encontrados na forma elementar (sem sofrer alterações) ou formando compostos. A presença de metais pesados no solo se apresenta como um componente natural ou como um resultado da atividade humana (RAMALHO, 1996).

Metais pesados formam um grupo de elementos com particularidades relevantes e de ocorrência natural no ambiente, como elementos acessórios na constituição de rochas. Esses elementos, apesar de associados à toxicidade, exigem tratamento diferencial em relação aos xenobióticos, uma vez que diversos metais possuem essencialidade comprovada para plantas ( $\mathrm{Ni}, \mathrm{Cu}$, $\mathrm{Fe}, \mathrm{Mn}, \mathrm{Zn}$ ) e animais (Ni, $\mathrm{Cu}, \mathrm{Fe}, \mathrm{Mn}, \mathrm{Zn}, \mathrm{Cr}$ ). Outra peculiaridade dos metais é o fato de não serem modificados ou degradados, como ocorre aos contaminantes orgânicos (BIONDI, 2010).

O solo possui uma grande capacidade de retenção de metais pesados, que, em função de suas características, podem ser facilmente lixiviados, penetrando na cadeia alimentar dos organismos vivos ou colocando em risco a qualidade das águas em aquíferos (CASARTELLI; MIEKELEY, 2003).

Algumas regiões detêm altíssimas concentrações desses contaminantes na sua forma solúvel. De origens diversas, tais compostos acumulam-se, em locais próximos a estradas, pela deposição de particulados poluídos que, posteriormente, são conduzidos pelas águas das chuvas, afetando vegetais, contaminando águas superficiais e profundas, e, desta forma, atingindo homens e animais
(FREIRE, 2005).

Esse mesmo autor afirma que a utilização de água de irrigação contaminada também é importante fonte de metais pesados, principalmente na cultura do arroz. A necessidade de resíduos industriais e domésticos utilizados como adubo orgânico é outra fonte possível. A necessidade de pesadas adubações de origem mineral, assim como os agrotóxicos e herbicidas, também acrescentam, ao solo, grandes quantidades de metal pesado.

A aplicação de insumos agrícolas aos solos e culturas tornou-se uma prática comum na agricultura. Os principais objetivos do uso desses agroquímicos são o aumento do suprimento de nutrientes, a correção do $\mathrm{pH}$ do solo (fertilizantes e corretivos) e a proteção das lavouras pelo controle de patógenos e pragas (agrotóxicos). Essas práticas podem, entretanto, causar degradação química do solo, como resultado da acumulação de elementos e, ou, compostos em níveis indesejáveis (RAMALHO et al., 2000).

O transporte de contaminantes inorgânicos no solo não é facilmente medido. No entanto, o assunto é de grande importância, sobretudo quando considerados os riscos que estes podem acarretar à qualidade das águas superficiais e subterrâneas e os elevados custos usualmente envolvidos em operações de remediação (CETEM, 2008).

A contaminação do solo por metais pesados causa interferência nas diversas formas de vida e no funcionamento dos ecossistemas. Uma das principais consequências é a difícil revegetação de áreas contaminadas e, por isso, há grande interesse no papel de microrganismos do solo, capazes de minimizar a toxidez destes metais no ambiente, evidenciando sua importância no sistema (CABRAL et al., 2010).

Os fertilizantes, como não são suficientemente purificados durante o processo de manufatura, por razões econômicas, geralmente contêm diversas impurezas, entre elas os metais pesados (AMARAL SOBRINHO et al., 1992). Esses metais, frequentemente, fazem parte dos componentes ativos dos pesticidas (FRANK et al., 1976), sendo, segundo vários autores, a adição desses elementos nos solos agrícolas causada pelo uso repetido e excessivo de fertilizantes, pesticidas metálicos e resíduos orgânicos. (KABATA-PENDIAS; PENDIAS, 1984; TILLER, 1989; ALLOWAY, 1990; BLUME; BRÜMMER, 1991; GIMENO-GARCIA et al., 1996).

Com base no avanço tecnológico, é de consenso entre os cientistas que o próprio melhoramento genético convencional esgotou-se pela falta de variabilidade genética dentro das espécies. 
Os agrotóxicos, por exemplo, não têm sido mais eficientes para controlar insetos-praga e doenças das plantas, pois a velocidade com que adquirem resistência aos produtos químicos é maior do que a velocidade de elaboração de novas fórmulas de defensivos agrícolas por parte da indústria (MAIRESSE; COSTA, 2009).

Segundo Van Put et al. (1994), os metais pesados presentes no material de solo perdido por erosão, quando atingirem cursos d'água, poderão ser liberados com mudanças de certas condições físico-químicas do meio, tais como: $\mathrm{pH}$, potencial de oxirredução e força iônica. Segundo esses pesquisadores, os processos de oxirredução e o pH são os mais importantes nas mudanças de solubilidade desses metais absorvidos na superfície de óxidos de Fe e Mn, que são fases do solo passíveis de sofrer redução, podendo ser liberados ao sofrerem mudanças no potencial redox, tornando-se, por isso, perigosos nessas condições redutoras (PARDO et al., 1990). Entretanto, a solubilidade dos metais pesados existentes nos sedimentos de rios, ao serem depositados na superfície do solo, dependerá da facilidade com que esses metais possam sofrer remobilização.

Outra fonte que se destaca nas alterações das propriedades químicas do solo, segundo Andrade et al. (2009), é a intensificação das atividades industriais, agrícolas e de urbanização, que aumentam o risco de poluição dos solos por metais pesados. Entre as atividades industriais, destaca-se a metalúrgica de metais pesados, que produz grandes quantidades de rejeitos ricos nesses poluentes.

Portanto, sob condições de oxidação, a solubilidade dos metais pesados dos sedimentos de rios pode ser reduzida, ocorrendo mudanças através da passagem gradual desses elementos, ligados a sulfetos metálicos para carbonatos, oxidróxidos, óxidos ou silicatos. As frações trocáveis e ligadas a carbonato poderão liberar os metais mais facilmente por efeito da diminuição do $\mathrm{pH}$ (ALLOWAY, 1990).

O solo foi considerado, por muito tempo, um receptor ilimitado de materiais descartáveis, como o lixo doméstico, os efluentes e os resíduos industriais, com base na suposição de que este meio apresenta uma capacidade ilimitada de atenuação das substâncias nocivas presentes, que levaria ao saneamento dos impactos criados. Essa capacidade, como ficou comprovada, é limitada (CETESB, 2007).

Com isso, grandes esforços têm sido feitos para integrar conhecimentos que facilitem a reabilitação de solos contaminados com metais pesados e, assim, possibilitar o retorno da funcionalidade e da estabilidade do ecossistema (ANDRADE et al., 2009).

Segundo a CETESB, o emprego de lista de valores orientadores de metais tem sido prática frequente em países com tradição na questão de monitoramento da qualidade de solos e águas subterrâneas, e, também, no controle ambiental.

Segundo a CETESB, é a concentração de determinada substância no solo que define um solo como limpo. Tal concentração, então, é um valor de referência de qualidade do solo. Os valores de prevenção indicam a concentração de determinada substância, acima da qual podem ocorrer alterações prejudiciais à qualidade do solo. Este valor indica a qualidade de um solo capaz de sustentar suas funções primárias, protegendo-se os receptores ecológicos.

Os valores de intervenção indicam que a concentração de determinada substância no solo acima da qual existem riscos potenciais, diretos ou indiretos, à saúde humana, considerando um cenário de exposição genérico (CETESB, 2005).

O solo atua, frequentemente, como um "filtro", tendo a capacidade de depuração, imobilizando grande parte das impurezas nele depositadas. No entanto, essa capacidade é limitada, podendo ocorrer alteração da qualidade do solo, devido ao efeito cumulativo da deposição de poluentes atmosféricos, aplicação de defensivos agrícolas, fertilizantes, disposição de resíduos sólidos industriais, urbanos, materiais tóxicos e radioativos.

\section{CONCLUSÕES}

As ações do ser humano levam a uma constante modificação do ambiente, podendo estas trazer benefícios ou não. Sua atuação de forma sustentável, como no caso dos comitês de bacia, possibilita o planejamento e a gestão dos recursos disponíveis.

A partir de um planejamento adequado podem ser evitadas áreas de vulnerabilidade ambiental dentro da bacia hidrográfica, dando a elas usos compatíveis com o seu estado atual, além da realização de estudos a fim de identificar os fatores que estão desencadeando esse quadro de vulnerabilidade ambiental, para, então, buscar alternativas de remediação.

A análise das áreas de vulnerabilidade ambiental torna-se uma ferramenta valiosa, pois auxilia o gestor na tomada de decisões, minimizando, assim, os erros de julgamento e otimizando o processo. 


\section{REFERÊNCIAS}

ALLER, L.; BENNET, T.; LEHR, J. H. \& PETTY, R. J. DRASTIC: A standardized system for evaluating groundwater pollution potencial using hydrogeologic settings. (U.S. EPA Report 600/2-85/018). 1987.

ALLOWAY, B. J. Heavy metals in soils. John Wiley and Sons, Inc. New York, 1990.

ALVES, M. C. Recuperação do subsolo de um Latossolo Vermelho usado para terrapleno e fundação da usina hidrelétrica de Ilha Solteira, SP. Ilha Solteira. Ilha Solteira: UNESP, 83p. Tese Livre Docente. 2001.

AMARAL SOBRINHO, N. M. B.; GOMES, M. F.; VELLOSO, A. C. X.; OLIVEIRA, C. de . Metais pesados em alguns fertilizantes e corretivos. R. Bras. Ci. Solo, n. 16, p. 271-276, 1992.

ANDERSON, L. O. SHIMABUKURO, Y. E. ; DEFRIES, R. S. ; MORTON, D. ; ESPIRITOSANTO, F. ; JASINSKI, E. ; HANSEN, M. C. Utilização de dados multitemporais do sensor MODIS para o mapeamento da cobertura e uso da terra. In: SIMPÓSIO BRASILEIRO DE SENSORIAMENTO REMOTO, 12. Goiânia. Anais... Goiânia, 2005, p. 3443-3450. 2005.

ANDRADE, M. G. de.; Melo, V. De. F.; Gabardo, J.; Souza, L. C, De. P. \& Reissmann, C. B. Metais Pesados Em Solos De Área De Mineração E Metalurgia De Chumbo. I - Fitoextração. R. Bras. Ci. Solo, 33: 1879-1888. 2009.

ANKENY, M. D.; KASPAR, T. C.; HORTON, $\mathrm{R}$. Caracterization of tillage and traffic effects on unconfined infiltration measurement. Soil Science Society of American Journal, v. 54, p. 837-840, 1990.

BELTRAME, A. V. Diagnóstico do meio físico de bacias hidrográficas: modelo e aplicação. Florianópolis: editora da Universidade UFSC. 112p. 1994.

BIONDI, C. M. Teores Naturais De Metais Pesados Nos Solos De Referência Do Estado De Pernambuco. Programa de Pós-Graduação em Ciência do Solo, Universidade Federal de Pernambuco, Tese de Doutorado, 58 p. 2010.

BLUME, H. P.; BRÜMMER, G. Predictions of Heavy Metals Behavior in Soil by Means of Simple Field Test. Ecotoxicol. Environ. Saf., v. 22, p. 164-
174, 1991

BOTELHO, R. G. M.; SILVA, A. S. Bacia Hidrográfica e Qualidade Ambiental. Reflexões sobre a Geografia Física no Brasil. 1. ed. Rio de Janeiro: Bertrand Brasil, 2004.

BRADY, N.C. Natureza e Propriedades dos Solos. Rio de Janeiro: Freitas Bastos, 1989.

CABRAL, L.; SIQUEIRA, J. O. SOARES, C. R. F. S.; BRASIL, J.E.P.P. Retenção De Metais Pesados Em Micélio De Fungos Micorrízicos Arbusculares. Química Nova (Impresso), v. 33, p. 25-29, 2010.

CARDOSO, M. L. de M. Desafios e potencialidades dos comitês de bacias hidrográficas. Cienc. Cult. vol.55, n 4, São Paulo. 2003.

CASARTELLI, E. A.; MIEKELEY, N. Determination of thorium and light rare-earth elements in soil water and its humic fraction by ICP-MS and on-line coupled size exclusion chromatography. Anal Bional Chem, 2003. Impress.

\section{CENTRO DE TECNOLOGIA MINERAL -} CETEM. Transporte de Metais Pesados no Solo no Contexto da Disposição de Resíduos Sólidos. Rio de Janeiro: CETEM/MCT, 2008.

\section{COMPANHIA DE TECNOLOGIA DE SANE-} AMENTO AMBIENTAL - CETESB. Valores Orientadores Para Solos e Águas Subterrâneas no Estado de São Paulo, São Paulo, 2005. Disponível em: <http://www.cetesb.sp.gov.br/Solo/relatorios/ tabela_valores_2005.pdf>. Acesso em: 28 set. 2013.

COMPANHIA DE TECNOLOGIA DE SANEAMENTO AMBIENTAL - CETESB. Relação de áreas contaminadas. 2007. Disponível em: <http:// www.cetesb.sp.gov.br/Solo/areas_contaminadas/ relacao_areas.asp>. Acesso em: 28 set. 2013.

CORSEUIL, C. W. Técnicas de geoprocessamento e de análise de multicritérios na adequação de uso das terras. 2006. $101 \mathrm{f}$. Tese (Doutorado em Agronomia/Energia na Agricultura)-Faculdade de Ciências Agronômicas, Universidade Estadual Paulista, Botucatu, 2006.

COSTA, F. J. L. Debates. In: MONTICELI, João Jerônimo (Coord.). Organismos de Bacias Hidrográficas. Rio de Janeiro: Semads, p. 17-28, 2002.

CRUVINEL, D. F. C. Avaliação Da Fitorremedia- 
ção Em Solos Submetidos À Contaminação Com Metais. 2009. 79f. Tese (Mestrado em Tecnologia Ambiental) - Universidade de Ribeirão Preto, Ribeirão Preto, 2009.

CURY, J. F. A Gestão Integrada de Bacias Hidrográficas: A Abertura de uma oportunidade para o Desenvolvimento Sustentável do Alto Paranapanema (1994-2004). Tese de Doutorado em Estruturas Ambientais Urbanas, Faculdade de Arquitetura e Urbanismo, Universidade de São Paulo, São Paulo, 350p, 2005.

CUTRIM, A. O.; CAMPOS, J. E. G. Avaliação da vulnerabilidade e perigo à contaminação do aquífero furnas na cidade de Rondonópolis (MT) com aplicação dos métodos GOD e POSH. In: Revista Geociências, São Paulo v.29, p. 401-411, 2010.

DEXTER, A. R. Soil physical quality. Part I. Theory, effects of soil texture, density, and organic matter, and effects on root growth. Geoderma, v. 120, p. 201-214, 2004.

DONHA, A. G.; SOUZA, L. C. de P.; SUGAMOSTO, M. L. Determinação da fragilidade ambiental utilizando técnicas de suporte à decisão e SIG. Revista Brasileira de Engenharia Agrícola e Ambiental, v.10, n.1, p.175-181, 2006.

DULAC, V. F. et al. Classificação das deliberações e projetos aprovados pelo Comitê de Bacia Hidrográfica do Rio Santa Maria. $3^{\circ}$ Congresso Internacional de Tecnologias para o Meio Ambiente, Bento Gonçalves, 2012.

FASSBENDER, H. W. Química de suelos, con ênfasis en suelos de América Latina. San Jose: IICA. 1982.

FEITOZA, M. Z. N. Estimativa da porosidade drenável por diferentes metodologias. Dissertação (Mestrado em Ciência do Solo) - Universidade Federal de Pernambuco, João Pessoa, 2006.

FIORIN, T. T. Estimativa da infiltração de água no solo a partir de pedofunções. 2008. 116f. Tese (Doutorado em Ciência do Solo) - Universidade Federal de Santa Maria, Santa Maria, 2008.

FLORIANO, E. P. Planejamento Ambiental. Caderno Didático no 6, $1^{\text {a }}$ Ed. Santa Rosa, 2004.

FOSTER, S. S. D.; HIRATA, R. C. A. Determinação do risco de contaminação das águas subterrâneas: um método baseado em dados existentes. São Paulo: Instituto Geológico, 1993.

FOSTER, S.; HIRATA, R.; GOMES, D.; D'ELIA, M.; PARIS, M. Protección de la calidad del água subterránea. Guia para empresas de água, autoridades municipales y agencias ambientales. Edición en español. 2003.

FRANÇA, D. de A.; FERREIRA, N. J. Considerações sobre o uso de satélites na detecção e avaliação de queimadas. In: SIMPÓSIO BRASILEIRO DE SENSORIAMENTO REMOTO, 12., 2005, Goiânia. Anais... Goiânia, 2005.

FRANK, R.; ISHIDA, K.; SUDA, P. Metals in Agricultural Soils of Ontario. Can. J. Soil Sci., v. 56, p. 181-196, 1976.

FREIRE, J. C. Condutividade hidráulica e capacidade de campo em um Latossolo Roxo distrófico não saturado. R. Bras. Ci. Solo, v. 3, p. 73-77, 1979.

FREIRE, M. De F. I. Metais pesados e plantas medicinais. Revista científica eletrônica de agronomia, ANO IV, Número 08, Dezembro 2005.

GALVÍNCIO, J. D.; SÁ, I. I. S.; MOURA, M. S. B. de; RIBEIRO, J. G. Determinação das características físicas, climáticas e da paisagem da bacia hidrográfica do rio Brígida com o auxilio de técnicas de geoprocessamento e sensoriamento remoto. Revista de Geografia. Recife: UFPE - DCG/NAPA, v. 24, no 2, mai/ago. 2007.

GIMENO-GARCIA, E.; ANDREU, V.; BOLUDA, $R$. Heavy metals incidence in the application of organic fertilizers and pesticides to rice farming soils. Environ. Poll., n. 92, p. 19-25, 1996.

GLOAGUEN, T. V.; PEREIRA, F.A.C.; GONÇALVES, R.A.B.; PAZ, V. da S. Composição química da solução do solo nas diferentes classes de poro do solo. R. Bras. Ci. Solo (Impresso), v. 33, p. 11051113, 2009.

GUERRA, A. J. T.; CUNHA, S. B. Degradação Ambiental. 1. ed. Rio de Janeiro: Bertrand Brasil, 1996.

GUERRA, H. O. C. Física dos solos. Campina Grande: UFPB, 2000. 173p.

HORTON, R. E. The role of infiltration in the hydrologic cycle. Trans. Amer. Geoph. Union, v. 14, 
p. 446-460. 1933.

KABATA-PENDIAS, A.; PENDIAS, H. Trace elements in soils and plants. Boca Raton, CRC Press, 1984.

KEMERICH, P. D. da C.; DESCOVI FILHO, L. V.; UCKER, F. E; FOLETTO, C. V. Influência dos

cemitérios na contaminação da água subterrânea em Santa Maria - RS. In: Revista Águas Subterrâneas, São Paulo, v. 24, p. 129-141, 2010.

KEMERICH, P. D. C.; SILVA, J. L. S. ; DESCOVI FILHO, L. L. V; SAUCEDO, E. M. Determinação da vulnerabilidade natural à contaminação da água subterrânea no bairro nossa senhora do perpétuo socorro em Santa Maria - RS. Engenharia Ambiental (Online), v. 8, p. 085-098, 2011.

LANNA, A. E. A Inserção da Gestão das Águas na Gestão Ambiental, in Interfaces da Gestão de Recursos Hídricos Desafios da Lei de Águas em 1997, Ministério do Meio Ambiente - MMA, p. 77 - 109, Brasil, 2000.

LIMA, V. C.; LIMA, J. M. J. C. Introdução à pedologia. Curitiba, Universidade Federal do Paraná, Dep. de Solos e Engenharia Agrícola, 1996.

LIMA, V. C.; LIMA, J. M. J. C. Fundamentos de Pedologia. Curitiba: Universidade Federal do Paraná, 2000.

LIMA, J. de O. Índice de qualidade ambiental para o município de Morrinhos. In: EREGEO - SIMPÓSIO REGIONAL DE GEOGRAFIA, 10. UFG. Anais... Catalão, 2007.

LIMA, W. De P. Hidrologia Florestal Aplicada ao Manejo de Bacias Hidrográficas. Piracicaba: USP, 2008.

LINHARES, C. de A.; SOARES, J. V.; BATISTA, G. T.. Influência do desmatamento na dinâmica da resposta hidrológica na bacia do Ji-Paraná. In: SIMPÓSIO BRASILEIRO DE SENSORIAMENTO REMOTO, 12. Goiânia, Anais... INPE, 2005.

MACEDO, R. K. Equívocos e propostas para a avaliação ambiental. In: TAUK, S. M. Análise Ambiental: uma visão multidisciplinar. 2. ed. São Paulo: Editora da Universidade Estadual Paulista. 1995.

MASCARENHAS, A. C. Comitê de Bacia Hidro- gráfica: O Que é, Como Funciona, e que Papel Desempenha na Gestão dos Recursos Hídricos. In: Plenarium, ano III, n. 3. Brasília: Câmara dos Deputados, Coordenação de Publicações, 2006.

MAIRASSE, L. A. S.; COSTA, E. C. Contaminação ambiental pela agricultura e as novas perspectivas com a moderna biotecnologia. Santa Maria: Orium, 2009.

MEIER, M. A. A conjuntura dos instrumentos da política estadual de recursos hídricos do estado do Rio Grande do Sul. 238 p. Dissertação (Mestrado). Universidade Federal de Santa Maria, Centro de Ciências Naturais e Exatas, Programa de Pós-Graduação em Geografia e Geociências, RS, 2011.

MESQUITA, M. G. B. F.; M. S. O. A dependência entre a condutividade hidráulica saturada e atributos físicos do solo. Revista Ciência Rural. 2004.

MONTEBELO, L. A.; CASAGRANDE, C. A.; BALLESTER, M. V. R.; VOCTORIA, R. L.; CUTOLO, A. P. A. Relação entre uso e cobertura do solo e risco de erosão nas áreas de preservação permanente na bacia do ribeirão dos Marins, Piracicaba-SP. In: SIMPÓSIO BRASILEIRO DE SENSORIAMENTO REMOTO, 12., 2005, Goiânia. Anais... Goiânia, 2005.

NASCIMENTO, W. M. do; VILLAÇA, M. G. Bacias hidrográficas: planejamento e gerenciamento. Revista Eletrônica da Associação dos Geógrafos Brasileiros - Seção Três Lagoas, MS, $\mathrm{N}^{\circ} 7$, ano 5 , 2008. Disponível em: <http://www.cptl.ufms.br/ revista-geo/Art507_W.Nascimento_M.Vila\%E7a. pdf $>$. Acesso em 25 abr. 2013.

NOBRE, M. F. O Zoneamento Ecológico-Econômico como Instrumento de Planejamento e Gestão Ambiental: uma proposta para a Bacia Hidrográfica do Rio Corumbataí (SP). 2008. 248 f. Tese (Doutorado em Geociências e Meio Ambiente) - Instituto de Geociências e Ciências Exatas, Universidade Estadual Paulista, Rio Claro, 2008.

OR, D.; WRAITH, J. M. Soil water content and water potential relationships. In: SUMNER, M. E. (Ed.) Handbook of Soil Science. Boca Raton, Washington. 2000.

OSÓRIO, Q. da S. Vulnerabilidade Natural de Aquiferos e Potencial de Poluição das Águas Subterrâneas. 2004. 139f. Dissertação (Mestrado em Geografia) - Universidade Federal de Santa Maria, 
Santa Maria, 2004.

PAIM, P. Paulo Paim: Entrevista [julh. 2010]. Entrevistador: M. A. Meier. Porto Alegre: DRH-RS, 2010. $1 \mathrm{~cd}$ sonoro. Entrevista concedida ao projeto "A conjuntura dos instrumentos de gestão da Legislação dos Recursos Hídricos no Estado do Rio Grande do Sul". 2010.

PAIVA, J. B. D.; PAIVA, E. M. C. D. Hidrologia aplicada a gestão de pequenas bacias hidrográficas. Porto Alegre: ABRH, 2001.

PANACHUKI, E. Infiltração de água no solo e erosão hídrica, sob Chuva simulada, em sistema de integração agricultura-pecuária. 2003. 67 f. Dissertação (Mestrado em Agronomia) - Universidade Federal De Mato Grosso Do Sul, Dourados, 2003.

PARDO, R.; BARRADO, E.; PÉREZ, L.; VEGA, $M$. Determination and speciation of heavy metals in sediments of the Pisuerga river. Water Res., n. 24, p. 373-379, 1990.

PORTO, M. F. A.; PORTO, R. L. L. Gestão de bacias hidrográficas. Estud. Av., vol.22, nº.63, 2008.

RAMALHO, J. F. G. P. Metais pesados em solos com diferentes usos agrícolas no Estado do Rio de janeiro. 145p. Tese (PhD) - UFRRJ, Rio de Janeiro: 1996.

RAMALHO, J. F. G. P.; AMARAL SOBRINHO, N. M. B. do; VELLOSO, A. C. X. . Contaminação da microbacia de Caetés com metais pesados pelo uso de agroquímicos. Pesquisa Agropecuária Brasileira, Brasília, v. 35, n.7, p. 1289-1303, 2000.

REICHARDT, K. A água em sistemas agrícolas. São Paulo: Manole, 1990.

REINERT, D. J.; REINERT, J. M. Propriedades físicas do solo. Universidade Federal de Santa Maria, RS - Apostila. 18p. 2006.

RIBEIRA, F. Calidad, contaminación y protección de acuíferos In: Curso Hispanoamericano De Hidrología Subterránea, 3., 2004, Montevideo. Anais... UY, 2004.

RICHART, A.; TAVARES FILHO, J.; BRITO, O. R.; LLANILLO, R. F.; FERREIRA, R. Compactação do solo: causas e efeitos. Semina, v. 26, p. 321-344, 2005.
ROCHA, A. A. Controle e Qualidade do Solo, Manole: São Paulo, 2005.

ROSA, R., BRITO, J. L. S., LIMA, E. F., SIQUEIRA, C. A., MACEDO, D. Elaboração de uma base cartográfica e criação de um banco de dados georreferenciados da Bacia do Rio Araguari MG. In: Gestão ambiental da bacia do Rio Araguari - rumo do desenvolvimento sustentável. Lima, S. C., Santos, R. J. (organizadores). Uberlândia, Universidade Federal de Uberlândia - Instituto de Geografia; Brasília: CNPq, p. 69-88, 2004.

ROSA, R. A. Introdução ao Sensoriamento Remoto. 6. ed. Uberlândia: EDUFU, 2007.

SANTOS, J. Ocupação do solo e comportamento hidrológico da sub-bacia do rio Luís Alves, bacia do Itajaí, Santa Catarina. 199p. Curitiba, PR. 2003. 1 v. Dissertação (Mestrado) - Universidade Federal do Paraná. Programa de Pós-Graduação em Engenharia Florestal. UFPR. 2003.

SANTOS, L. J. C.; FIORI, C. O.; CANALLI, N. E.; FIORI, A. P.; SILVEIRA, C. T. da; SILVA, J. M. F. da. Mapeamento da vulnerabilidade geoambiental do estado do Paraná. In: Revista Brasileira de Geociências, v. 37 (4), 2007. pp. 812-820.

SANTOS, R. A.; CRUZ, M. J. M.; NASCIMENTO, S. A. M. Avaliação da vulnerabilidade natural de aquíferos cársticos: subsídios para uma gestão dos recursos hídricos subterrâneos. Cadernos de Geociências, 2010.

SCHLINDWEIN, J. R.; DURANTI, R. R.; CEMIN, G.; AHLERT, S.; FALCADE, I. Mapeamento do uso e cobertura do solo do município de Caxias do Sul (RS) através de imagens do satélite CBERS. In: Simpósio Brasileiro de Sensoriamento Remoto, 13., 2007, Florianópolis. Anais... Florianópolis, 2007.

\section{SECRETARIA ESTADUAL DO MEIO}

AMBIENTE - SEMA. Porto Alegre - RS, 2004. Disponível em: <http//www.sema.rs.gov.br>. Acesso em: 28 set. 2013.

\section{SECRETARIA ESTADUAL DO MEIO}

AMBIENTE - SEMA. Relatório Anual Sobre a Situação dos Recursos Hídricos no Estado do Rio Grande Do Sul Edição 2007/2008. Rio Grande do Sul, 2008.

SILVA, C. L.; KATO, E. Efeitos do selamento 
superficial na condutividade hidráulica saturada da superfície de um solo sob cerrado. Pesquisa Agropecuária Brasileira, v. 31, p. 593-597, 1997.

SILVA, R. C. A.; ARAUJO, T. M. Qualidade da água do manancial subterrâneo em áreas urbanas de Feira de Santana (BA). Ciência \& Saúde Coletiva, v. 8 n. 4, p. 1019-1028. 2003.

SILVA, A. M. D.; SCHULZ, H. E.; CAMARGO, P. B. Erosão e hidrossedimentologia em bacias hidrográficas. São Carlos: RiMa, 2004.

STONE, L. F.; MOREIRA, J. A. A. Efeitos do sistema de preparo do solo no uso da água e na produtividade do feijoeiro. Pesquisa Agropecuária Brasileira, Brasília, v. 35, n. 4, p. 835-841, 2000.

STRECK, E. V.; KÄMPF, N.; DALMOLIN, R. S. D.; KLAMT, E.; NASCIMENTO, P. C. do; SCHNEIDER, P.; GIASSON, E.; PINTO, L. F. S. Solos do Rio Grande do Sul. 2.ed. rev. e ampl. Porto Alegre: Emater/RS, 2008. 222p.

TILLER, K.G. Heavy metals in soils and their environmental significance. In: TILLER, K.G. Advances in soil science. New York : Springer, 1989.

TUCCI, C. E. M. Coeficiente de Escoamento e Vazão Máxima de Bacias Urbanas. Revista Brasileira de recursos Hídricos, 5: 61-68. 2000.

USDA. National Engineering Handbook. Section 4, Hydrology. Soil Conservation Service. Washington, D.C., 1972.

VAN PUT, A.; GRIEKEN, R. V.; WILKEN, R. D.; HUDEC, B. Geochemical characterization of suspended matter and sediment samples from the Elbe river by EPXMA. Water Res., n. 28, p. 643-655, 1994.

ZAKIA, M. J. B. Identificação e caracterização da zona ripária em uma microbacia experimental: implicações no manejo de bacias hidrográficas e na recomposição de florestas. 1998. 113f. Tese (Mestrado em Engenharia Ambiental) - Programa de pósgraduação em Ciências da Engenharia Ambiental, Universidade de São Paulo, São Carlos, 1998. 